MATEC Web of Conferences 25, 04012 (2015)

DOI: $10.1051 /$ matecconf/ 20152504012

(C) Owned by the authors, published by EDP Sciences, 2015

\title{
Wave Analysis for West Coast of South Myanmar
}

\author{
Yanan Xu, Feng Gao, Ciheng Zhang \& Yingni Luan \\ Tianjin Research Institute for Water Transport Engineering, M.O.T, Tianjin, China
}

\begin{abstract}
The characteristic of southern parts of Myanmar is tropical monsoon climate, and this area is affected by few typhoons. The wave height is changed with season, the field measured data shows that the average monthly maximum wave height is in June. The wave height, swelling from Indian Ocean and spreading to research area, is small. The research adopts SWAN model to simulate the waves that are transformed from offshore to nearshore Myanmar based on the meteorological data from ECMWF. The simulated results were compared with satellite data and field measured data, it showed that the trend between the curves is unified, and the extreme value of simulation is close to the measured value. The simulation presents wave distribution around Myanmar southern sea, it shows that the wave height and wave directions are affected by terrain refraction and island trains shielding. When the wave is from WSW direction, the wave will be decreased fast caused by island shielding, and the direction turns to $\mathrm{W}$ direction at northern coastline. When the wave comes from SSW direction the island shielding will be weak, the wave will be decreased slowly, and the direction will turn to SW direction at southern coastline.
\end{abstract}

Keywords: typhoon; monsoon; satellite; SWAN

\section{INTRODUCTION}

West coast of south Myanmar faces Andaman Sea, and the research coast is near to Hngetthaik islands. The terrain of the studied sea area changes fast, and isobaths which are $-20 \mathrm{~m}$ are only $4 \mathrm{~km}$ away from the coastline. Andaman Sea is controlled by monsoon climate. The prevailing wind is from southwest direction in summer and from northeast direction in winter [1]. Though Andaman Sea is connected with Bay of Bangle, typhoon often affects this Bay, and less strong typhoon passed the research sea area. According to reanalysis data from ECMWF, during the Southwest monsoon period, the frequency of $\mathrm{W}$ direction wind to $\mathrm{S}$ direction wind is equal to the frequency of $\mathrm{E}$ direction wind to $\mathrm{N}$ direction wind in May, and the strength is enhanced in W to S direction. From June to August, the prevailing wind is mainly in WSW direction, the maximum wind speed is $17.8 \mathrm{~m} / \mathrm{s}$. In September, the frequency of $\mathrm{E}$ direction wind to $\mathrm{N}$ direction wind is increased, but the strong wind still focuses on SW direction. During the northeast monsoon period, the frequency of $\mathrm{E}$ direction wind to $\mathrm{N}$ direction wind is increased from November to next January, and the strength is also enhanced. In January, the frequency of ENE wind reaches $21.6 \%$, and the maximum wind speed is $12.3 \mathrm{~m} / \mathrm{s}$.

According to the measured wave data (from 2012 to 2013), the research found that the period of the strong waves is from May to September. The wave height is small from October to next April. The results show that the wave height is obviously changed with the season. The average yearly significant wave height is $0.5 \mathrm{~m}$. From May to September, average monthly maximum wave height is all above $0.5 \mathrm{~m}$. And In June, average monthly maximum wave height reaches $1 \mathrm{~m}$. The yearly maximum significant wave height is $2 \mathrm{~m}$ in June and September.

\section{METHODOLOGY}

SWAN has been widely used to compute irregular waves in coastal environments and river mouth ${ }^{[2,3]}$. This model adopts spectrum action balance equations to describe wind wave generation and nearshore transformation. SWAN explicitly represented all relevant processes of wave propagation, wind generation, white capping, quadruplet wave-wave interactions and dissipation by wave breaking and bottom friction. Diffraction is included in an approximate manner. The model is fit for deep water conditions, transitional water depth and shallow water conditions, ${ }^{[4-6]}$.

(1)Wave action equilibrium equation

The evolution of the wave spectrum is described by the spectral action balance equation, which, for Cartesian coordinates, is (e.g. Hasselmann et al. 1973):

$\frac{\partial}{\partial t} N+\frac{\partial}{\partial x} C_{x} N+\frac{\partial}{\partial y} C_{y} N+\frac{\partial}{\partial \sigma} C_{\sigma} N+\frac{\partial}{\partial \theta} C_{\theta} N=\frac{S}{\sigma}(1)$

The first term on the left-hand side of Equation (1) represents the local rate of change of action density in time, the second and third term represent propagation of action in geographical space (with propagation velocities $C_{x}$ and $C_{y}$ in $x$ and $y$ space, re- 


\section{MATEC Web of Conferences}

spectively). The fourth term represents shifting of the relative frequency due to variations in depths and currents (with propagation velocity $C_{\sigma}$ in $\sigma$ space). The fifth term represents depth-induced and current-induced refraction (with propagation velocity $C_{\theta}$ in $\theta$ space). The expressions for these propagation speeds are taken from linear wave theory (e.g. Whitham, 1974, Dingemans, 1997). The term $S$ at the right-hand side of the action balance equation is the source term in terms of energy density, representing the effects of generation, dissipation, and nonlinear wave-wave interactions.

In Equation (1), the propagation velocities are calculated in linear wave theory:

$$
\begin{aligned}
& C_{x}=\frac{d x}{d t}=\frac{1}{2}\left[1+\frac{2 k d}{\sinh (2 k d)}\right] \frac{\sigma k_{x}}{k^{2}}+U_{x} \\
& C_{y}=\frac{d y}{d t}=\frac{1}{2}\left[1+\frac{2 k d}{\sinh (2 k d)}\right] \frac{\partial k_{y}}{k^{2}}+U_{y} \\
& C_{\sigma}=\frac{d \sigma}{d t}=\frac{\partial \sigma}{\partial d}\left[\frac{\partial d}{\partial t}+\vec{U} \cdot \bar{v} d\right]-C_{g} \vec{k} \cdot \frac{\partial \vec{U}}{\partial s} \\
& C_{\theta}=\frac{d \theta}{d t}=\frac{1}{k}\left[\frac{\partial \sigma}{\partial d} \frac{\partial d}{\partial m}+\vec{k} \cdot \frac{\partial \vec{U}}{\partial s}\right]
\end{aligned}
$$

Where, $\vec{k}=\left(k_{x}, k_{y}\right)$ is wave number; $d$ is wave depth; $\vec{U}=\left(U_{x}, U_{y}\right)$ is flow velocity; $\quad S$ is the space coordinates in $\theta$ directions; $m$ is coordinate perpendicular to $S$; the operator $\partial / \partial t$ is defined as: $\frac{\partial}{d t}=\frac{\partial}{d t}+\vec{C} \cdot \nabla_{x, y}$.

\section{FIELD WIND RESULTS}

Wind field ranges from $6^{\circ} \mathrm{N}-19^{\circ} \mathrm{N}, 87.75^{\circ} \mathrm{E}-101^{\circ} \mathrm{E}$. The essential wind data source is the global meteorological data from the European Centre for Medium-Range Weather Forecasts (ECMWF) in past 20 years, the spatial resolution is $0.75^{\circ} \times 0.75^{\circ}$, and time resolution is 6 hour. The research selected 20 bigger wind processes each year from 1993 to 2012, and refined the wind data in calculating area. They would be the input wind conditions for SWAN model. The refined wind field in August, 2007 is shown in the
Figure 1.

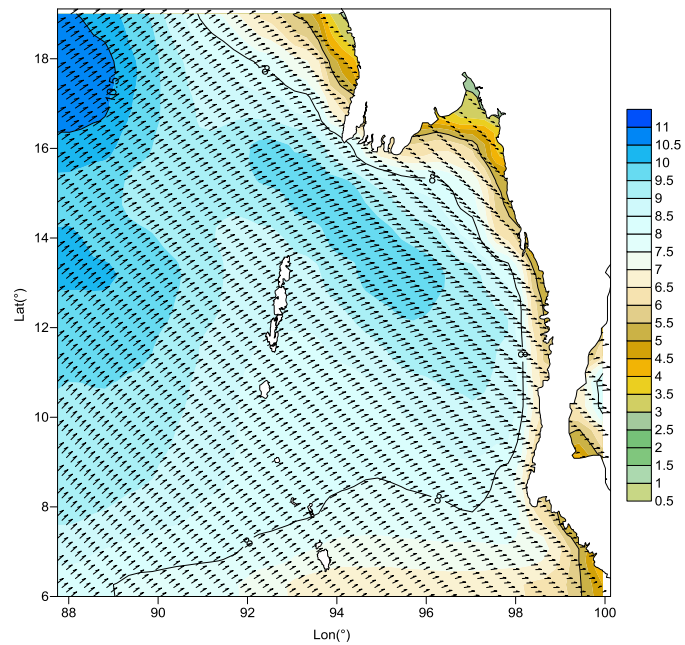

(1) 20070808_00UTC Wind field

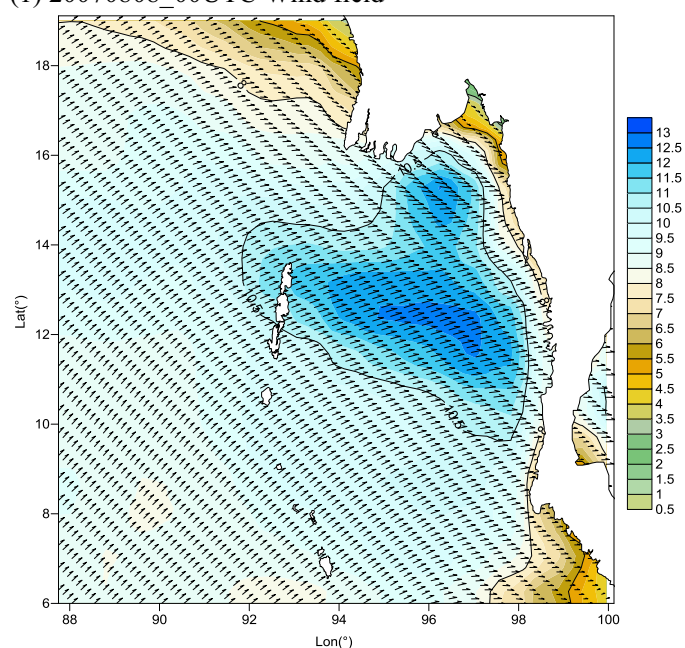

(2) 20070808 12UTC Wind field

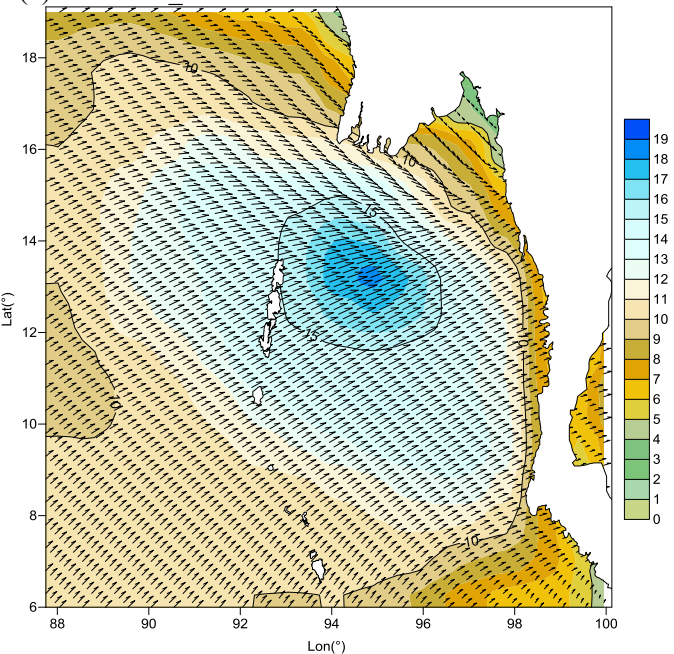

(3) 20070809 00UTC Wind field 


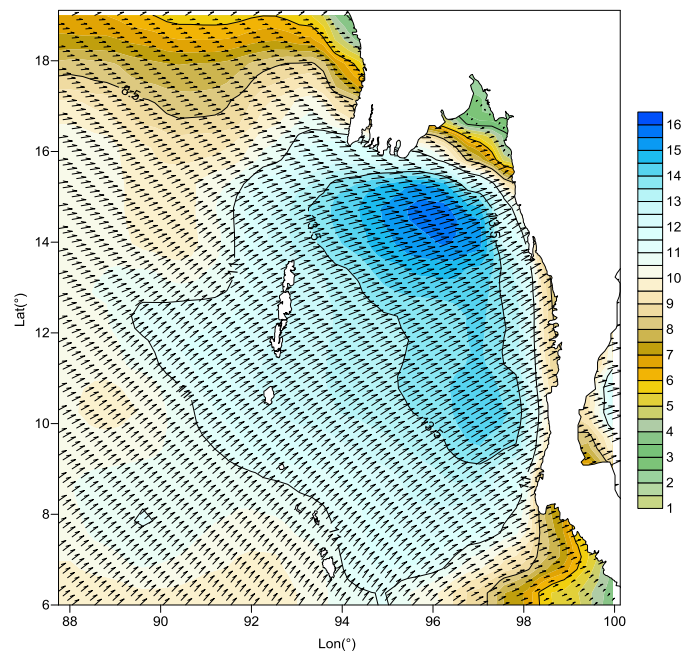

(4) 20070809 12UTC Wind field

Figure 1. Wind field maps (Wind speed: $\mathrm{m} / \mathrm{s}$ )

From the analyzed results, the yearly maximum wind data in the past 20 years $(1993-2012)$ are employed to estimate the wind speed in different return period. The probability graph of P-III distribution is in 4 different directions (W, WSW, SW and SSW). And the statistical result of wind data is shown in Table 1:

Table 1. Wind speed in different return period $(\mathrm{m} / \mathrm{s})$

\begin{tabular}{|c|c|c|c|c|}
\hline $\operatorname{Re(a)}$ Dir. & SSW & SW & WSW & W \\
\hline 50 & 20.57 & 23.73 & 24.67 & 22.72 \\
\hline 5 & 16.18 & 17.29 & 18.51 & 18.14 \\
\hline
\end{tabular}

\section{WAVE SIMULATION RESULT}

\subsection{Meshing}

The unstructured finite-element mesh of the studied domain is developed in order to reproduce the process of wave propagation. The spatial coverage of this mesh includes Andaman Sea and part Bay of Bengal. The ADCIRC model mesh of studied domain is shown in Figure 2. The triangular grids are employed in the mesh, which contain 73,554 nodes and 141,313 elements, with the maximum grid size which is $41 \mathrm{~km}$ in the boundary and the minimum grid size which is $14 \mathrm{~m}$ near the studied site.

\subsection{Verification}

Observed wave data from satellite are the most direct and reliable one to do comparison. The simulation results could be compared with Jason-2 (J2) satellite altimeter data. The repeated orbital period is about 10 days, and Figure 3 shows the satellite orbit which passes through Myanmar. When satellite passed through western sea of Myanmar, wave height would be recorded and compared with results of SWAN. The comparison had been shown in Figure 4 and Figure 5 $(19 / 07 / 2012$ and $05 / 06 / 2010)$. The graph shows that SWAN result fits well with satellite observed data.

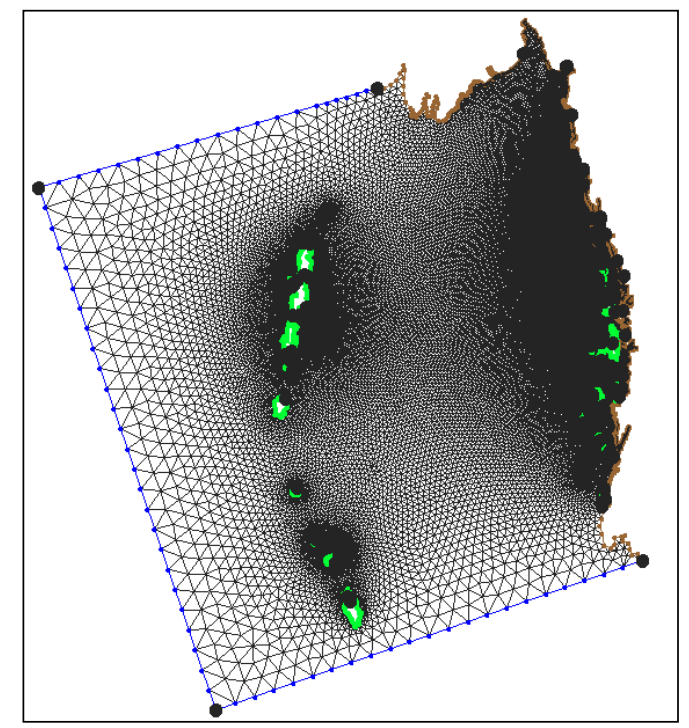

Figure 2. Meshing for studied area

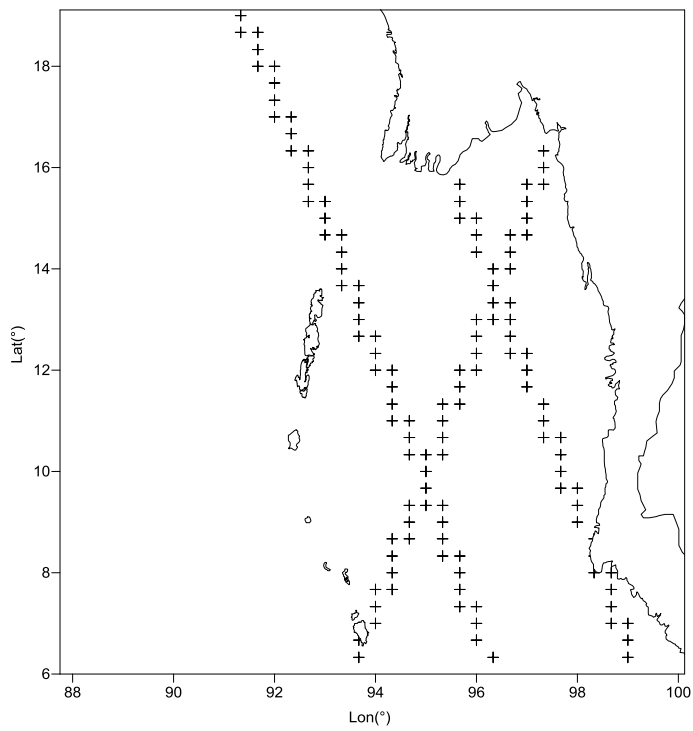

Figure 3. Tracks of satellite passed through Myanmar

The observed wave condition from March, 2012 to March, 2013 is also used to do the verification. The observed station located at $13^{\circ} 53.980 \mathrm{~N}, 9^{\circ} 03.833^{\prime} \mathrm{E}$, the water depth is $17.5 \mathrm{~m}$. The research compared several observed big wave height with SWAN result in 


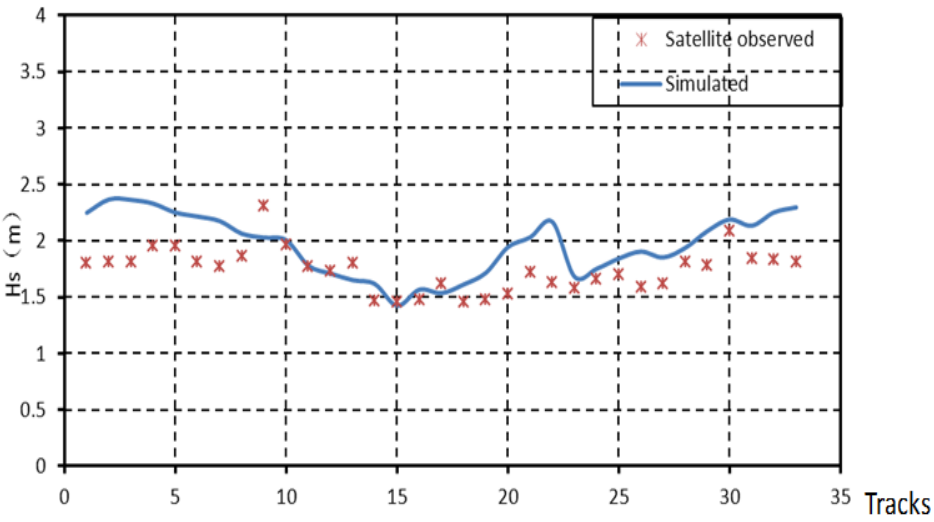

Figure 4. Comparison between satellite results and simulation results in July, 2012

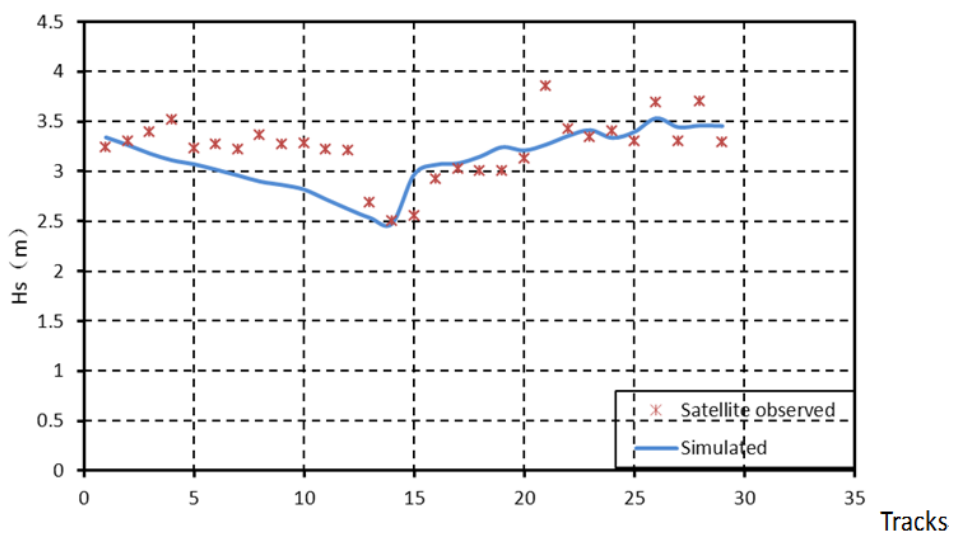

Figure 5. Comparison between satellite results and simulation results in June, 2010

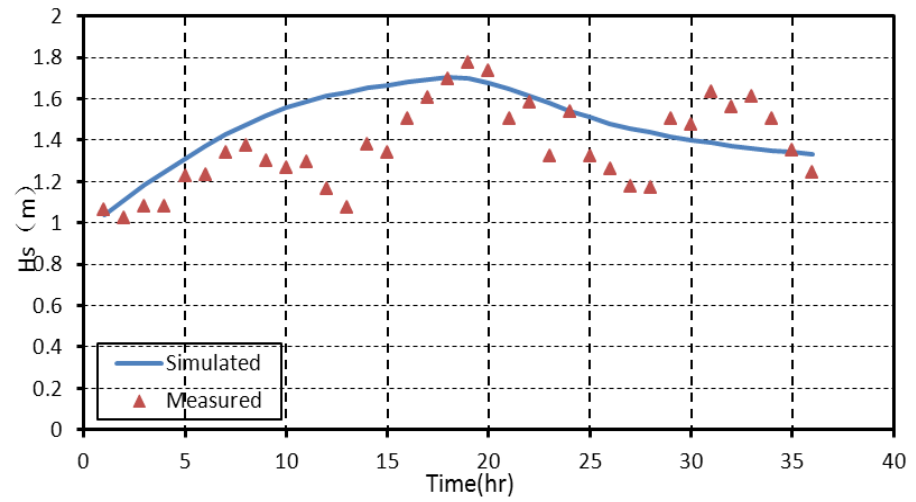

Figure 6. Comparison between measured value and simulation results in June, 2012

June, July and September. During June $6^{\text {th }}-8^{\text {th }}, 2012$, the observed significant wave height is about $1.8 \mathrm{~m}$, and simulated result is $1.7 \mathrm{~m}$. During July $17^{\text {th }}-19^{\text {th }}$, 2012 , the observed significant wave height is about $2 \mathrm{~m}$, and the simulated result is $2.1 \mathrm{~m}$. The comparison results are shown in Figure 6 and Figure 7. From the results, the simulated value fits well with observed data, and the maximum wave height is similar. Therefore, the simulated result is credible. 


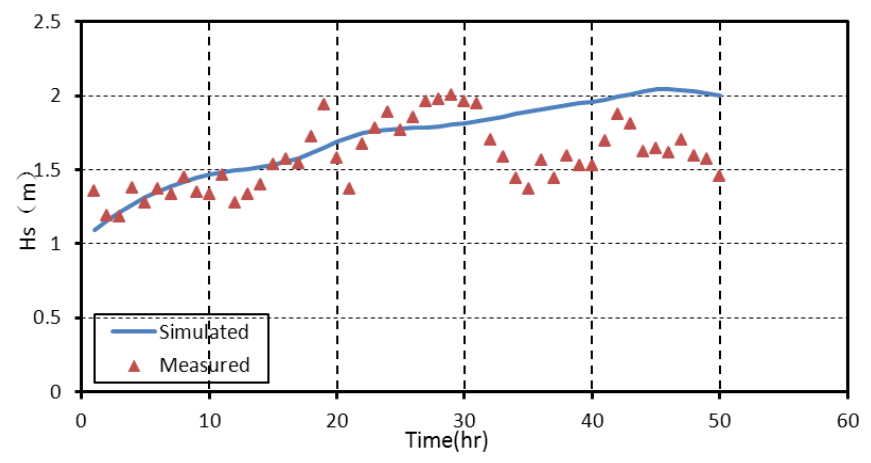

Figure 7. Comparison between measured value and simulation results in July, 2012

Table 2. 50yrs significant wave period result

\begin{tabular}{|l|l|l|l|l|}
\hline DIR. & SSW & SW & WSW & W \\
\hline Expected values(s) & 9.16 & 9.48 & 10.53 & 9.94 \\
\hline Confidence interval(s) & {$[7.53-10.79]$} & {$[7.85-11.11]$} & {$[8.9-12.16]$} & {$[8.31-11.57]$} \\
\hline
\end{tabular}

Table 3. Wave conditions in different return period

\begin{tabular}{|l|l|l|l|l|l|l|l|l|}
\hline \multirow{2}{*}{ RE. DIR. } & \multicolumn{2}{l|}{ SSW } & \multicolumn{2}{l|}{ SW } & WSW & W \\
\cline { 2 - 9 } & $\mathrm{Hs}(\mathrm{m})$ & $\mathrm{Ts}(\mathrm{s})$ & $\mathrm{Hs}(\mathrm{m})$ & $\mathrm{Ts}(\mathrm{s})$ & $\mathrm{Hs}(\mathrm{m})$ & $\mathrm{Ts}(\mathrm{s})$ & $\mathrm{Hs}(\mathrm{m})$ & $\mathrm{Ts}(\mathrm{s})$ \\
\hline $50 \mathrm{a}$ & 3.74 & 9.16 & 4.17 & 9.48 & 5.59 & 10.53 & 4.79 & 9.94 \\
\hline $5 \mathrm{a}$ & 2.93 & 8.57 & 3.17 & 8.75 & 4.22 & 9.52 & 3.7 & 9.14 \\
\hline
\end{tabular}

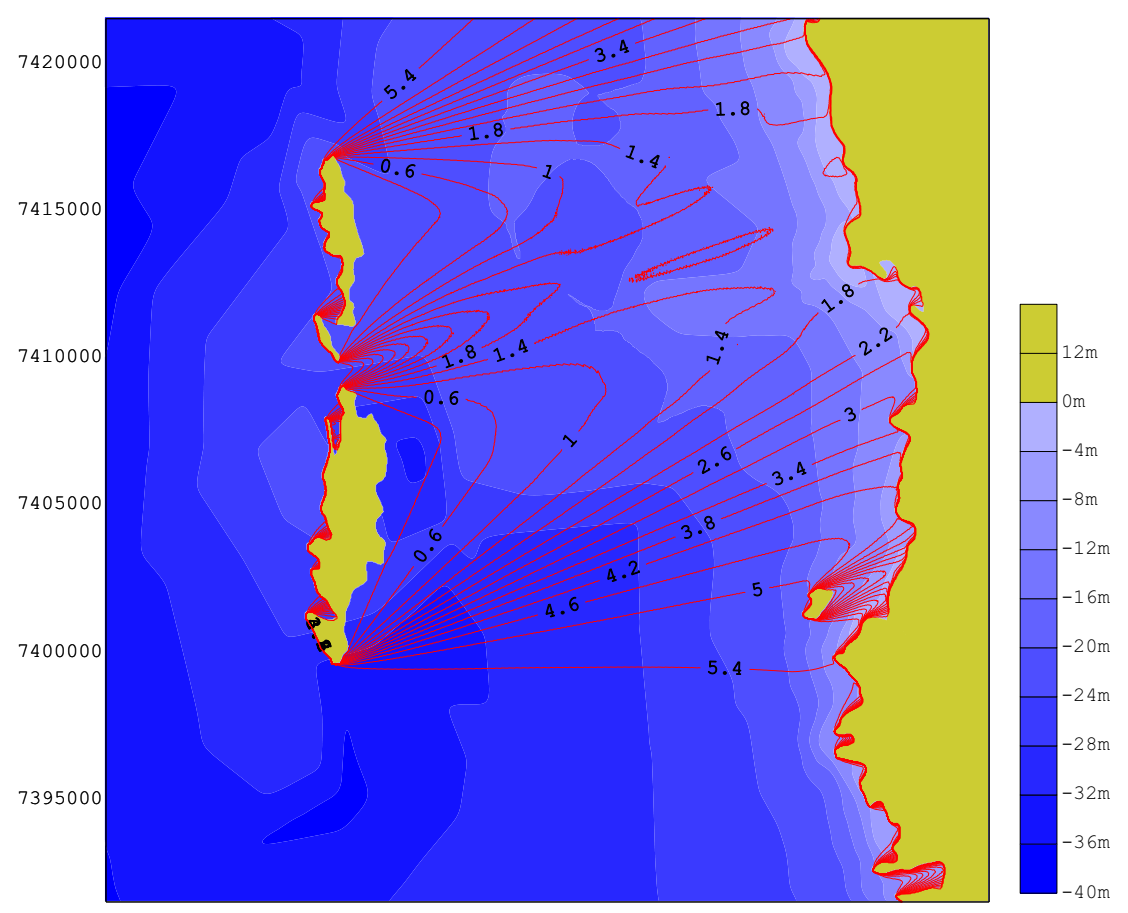

Figure 8.1 in 50 Significant wave height distribution in WSW direction (m) 


\section{MATEC Web of Conferences}

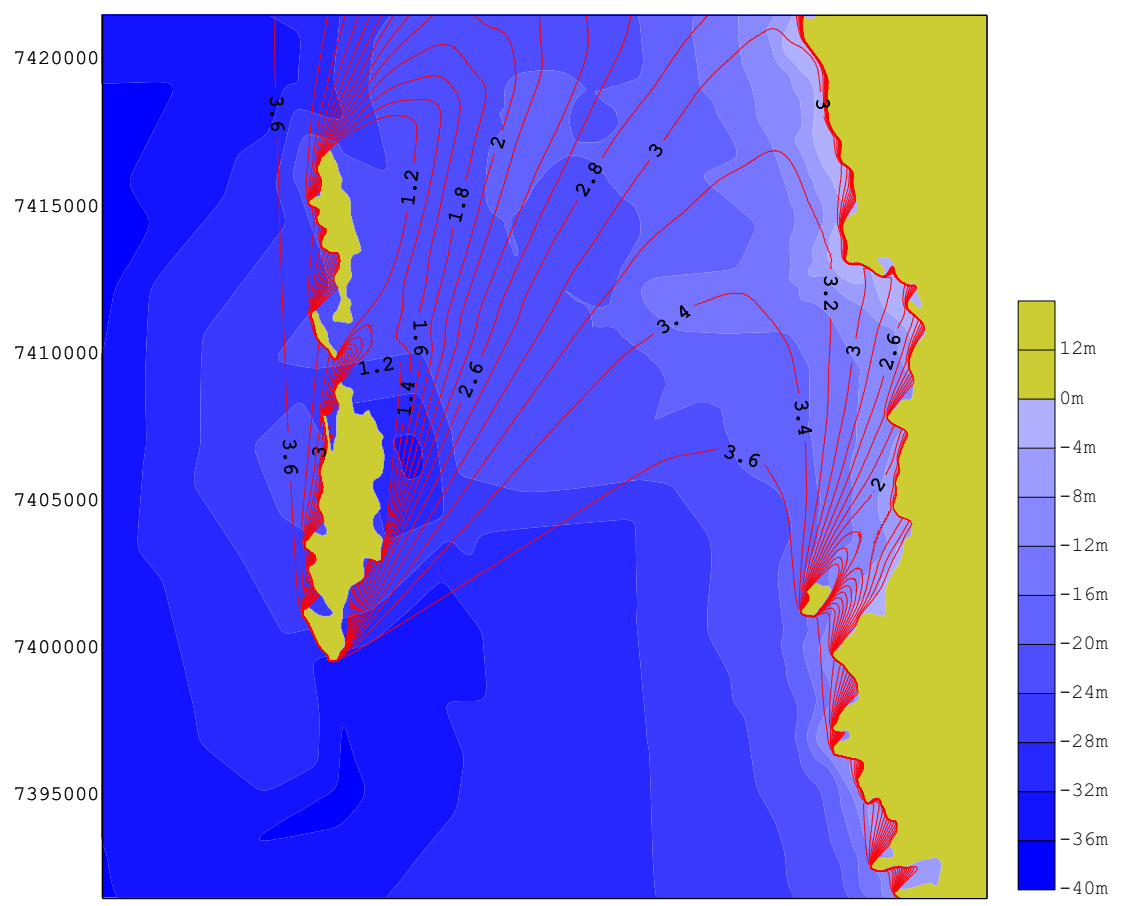

Figure 9. 1 in 50 Significant wave height distribution in SSW direction (m)

\subsection{Offshore wave results}

Based on observed wave conditions from March, 2012 to March, 2013, the study analyzed simultaneous distribution for wave height and wave period. The average significant wave height is $0.5 \mathrm{~m}$, and average wave period is $6.8 \mathrm{~s}$. From the results, the significant wave height is less than $0.5 \mathrm{~m}$, and the corresponding wave period range is wide. While significant wave height is higher, the corresponding wave period range is small, which is more close to wind wave period. It means that the project area may be influenced by long period wave from open sea, but the wave height is small. Waves that influenced project sea area are mostly wind waves. The expectancy value and confidence interval with 0.95 confidence probability for significant wave period in 50yr return period are shown in Table 2. The offshore wave conditions in different return period are shown in Table 3.

When waves are transformed from offshore to nearshore, significant wave height distribution in WSW and SSW directions is shown in Figure 8 and Figure 9. From the results of wave contour maps, it is obvious that the wave height is changed with the underwater topography, and the contour is gradually parallel with the shorelines. When wave comes from WSW direction with Hs $5.59 \mathrm{~m}$, the Hngetthaik islands shield against the waves at the back of the islands shadow region is formed. Parts of waves bypassed the islands and went directly to the shoreline. When the waves spread to nearshore area, the significant wave height is less than $1.4 \mathrm{~m}$ at the back of northern Hngetthaik. The wave direction changed is caused by wave diffraction and refraction, and the WSW waves are changed to $\mathrm{W}$ direction. When wave comes from SSW direction with $\mathrm{Hs} 3.74 \mathrm{~m}$, the incident wave direction is almost parallel with the islands, therefore, the shadow region at back of the islands is small, and most waves went shoreline directly; when waves spread to nearshore, significant wave height is about $3 \mathrm{~m}$, and wave turns to SW direction at the back of southern Hngetthaik due to the terrain refraction.

\section{CONCLUSION}

Andaman Sea is controlled by monsoon climate. The prevailing wind is from southwest direction in summer and from northeast direction in winter. Though Andaman Sea is connected with Bay of Bangle, typhoon often affects this Bay, and less strong typhoon passed the research sea area. According to wave analysis, the studied region aims at waves from SSW - WSW directions.

The research adopts SWAN model to simulate the waves which are transformed from offshore to nearshore. The simulated results were compared with satellite data and field measured data. From the results, the simulated value fits well with observed data, and the maximum wave height is similar. Therefore, the simulated result is credible.

When waves spread to nearshore, the WSW waves 
are changed to $\mathrm{W}$ direction at the back of northern Hngetthaik due to wave diffraction and refraction. The wave height shielding from the islands is decreased fast. When the incident wave comes from SSW directions, wave is changed to SW direction at the back of southern Hngetthaik. The shadow region formed along this direction is small, waves could go straight ahead shoreline, and the wave height is increased fast around the nearshore area.

\section{REFERENCES}

[1] Su Yuelei. 2006. The application of SWAN in Mymmar coastal area, Nanjing: Hehai University:1-10.

[2] XU Yanan, \& Feng Jianguo. 2014. Wave conditions simulation for sea area of Colombo port in Sri Lanka, Journal of waterway and Harbor. 35(4):312-316.
[3] Ou Shan-hwei, Liau Jian-ming, \& Hsu Tai-wen, et a1 2002. Simulating-phoon waves by SWAN wave model in coastal waters of Taiwan. Ocean Engineering, 29(1):947-971.

[4] Hao Yuchi, \& Tao Jianhua. 2007. The SWAN model used to study wave breaking, Port engineering technology, (1):4-6.

[5] Jiaxiao, \& Pan Junning. 2010. Improvement and validation of wind energy input in SWAN model. Journal Of Hohai University (Natural Sciences), 38(4):585-591.

[6] ZHENG Jin-hai, \& Le Ngoc Quy, et al. 2009. Comparisons of diffraction effects in two coastal spectral wave models, Journal of Transport Science and Engineering, 25(2):78-82.

[7] Yao Guoquan, \& Ding Bingcan et al. 1993. Statistic analysis of the annual extreme wave parameters for the coast of china. China Ocean Engineering, 7(1):109-116. 